\title{
Assessing water resources vulnerability and resilience of southern Taiwan to climate change
}

\author{
Ming-Hsu Li ${ }^{1, *}$, Kai-Jia Tseng ${ }^{1}$, Ching-Pin Tung ${ }^{2}$, Dong-Sin Shih ${ }^{3}$, and Tzu-Ming Liu ${ }^{4}$ \\ ${ }^{1}$ Graduate Institute of Hydrological and Oceanic Sciences, National Central University, Taoyuan City, Taiwan \\ ${ }^{2}$ Department of Bioenvironmental Systems Engineering, National Taiwan University, Taipei City, Taiwan \\ ${ }^{3}$ Department of Civil Engineering, National Chung Hsing University, Taichung City, Taiwan \\ ${ }^{4}$ National Science and Technology Center for Disaster Reduction, New Taipei City, Taiwan
}

\section{Article history:}

Received 17 November 2015

Revised 28 April 2016

Accepted 23 August 2016

Keywords:

Climate change, Water resources, Vulnerability, Resilience, Adaptation measures

Citation:

Li, M. H., K. J. Tseng, C. P. Tung, D. S. Shih, and T. M. Liu, 2017: Assessing water resources vulnerability and resilience of southern Taiwan to climate change. Terr. Atmos. Ocean. Sci., 28, 67-81, doi: 10.3319/ TAO.2016.08.23.02(CCA)

\begin{abstract}
Water resources management has become more challenging in Taiwan due to rapid socio-economic development and the complications of climate change. This study developed a systematic procedure for assessing water resources vulnerability and resilience with an integrated tool, TaiWAP, including climate change scenarios, a weather generator, a hydrological model, and system dynamic models. Five assessment indicators, including two for vulnerability, two for resilience, and one for availability were used to quantify changes in water resources and improvements after implementing adaption measures. Each indicator was presented with 3 grades, namely low, medium, and high. Water resources vulnerability and resilience for Tainan City in southern Taiwan were evaluated. Insufficient water supply facilities capacity is the major weakness causing low resilience. Water resources allocation flexibility is limited by substantial agricultural water demands. A total of 9 adaption measures and combinations of measures were assessed. Desalination plant implementation can steadily supply public water to lessen system failure duration. Although agricultural water conservation and fallow land can greatly reduce water demand, fallow compensation is a potential cost. When food security is considered, reducing irrigation leakage will be a better adaption measure to both water and agriculture stakeholders. Both agriculture water conservation and cropping systems adjustment have crossspatial flexibilities. The combination of desalination, reservoirs and public water conservation provide the most beneficial effects in reducing climate change impact.
\end{abstract}

\section{INTRODUCTION}

Although annual precipitation in Taiwan is abundant, the temporal distribution ratio of precipitation is 9:1 for wet (from May to October) and dry seasons in Southern Taiwan, causing floods in the wet season and drought in the dry season ( $\mathrm{Li}$ et al. 2009). Such uneven temporal distribution makes water resources management more difficult with climate change. The Intergovernmental Panel on Climate Change (IPCC) indicated that freshwater-related climate change risk has increased significantly with increasing greenhouse gas concentrations (IPCC 2014). Even if greenhouse gas emissions were stabilized or greatly reduced, the Earth's climate system will continue to change (Piao et al.

\footnotetext{
* Corresponding author

E-mail:mli@cc.ncu.edu.tw
}

2010). In addition, climate change is projected to have more extreme effects and significantly reduce renewable surface water and groundwater resources. This may expose human beings to greater risks of water scarcity, such as Tainan City with great wet to dry precipitation ratio.

Past studies have focused on the vulnerability and resilience of water resources and identified adaptation strategies against the impacts of climate change (Liu et al. 2009; Urich and Rauch 2014; Tung et al. 2014). Brenkert and Malone (2005) assessed the vulnerability of India using a Vulnerability-Resilience Indicator Prototype. Sullivan (2011) attempted to identify the current state of water vulnerability using a Water Vulnerability Index calculated based on supply-driven vulnerability and demand-driven vulnerability. To promote precise policy decisions and further achieve 
sustainable development, it is important to quantify water resources vulnerability and the improvements gained using different adaptation measures.

Tainan City has the largest irrigation system delivering great amounts of water for agricultural production in Southern Taiwan. In recent years, rapid population and economic growth with the development of the Southern Taiwan Science Park have resulted in increased water demand for domestic and industrial usage. Agriculture water demand slightly decreased due to the reduction in farming areas. However, such reduction is not enough to compensate for the increased demand for public water (domestic and industrial usage). Considering the effects of climate change, demand for agriculture water is sensitive to climate variations and farming seasons (Downing et al. 2003). Agriculture water supply is limited by the water availability influenced by climate change, hence affecting food production (Piao et al. 2010). Without sufficient agricultural water food security will be a great concern due to limited crop production (Yoo et al. 2012). As pointed out in the IPCC report, climate change might intensify competition regarding different water usage purposes. Allouche (2011) investigated the resilience and sustainability of water and food systems and concluded that both water and food security will face major challenges from climate change.

Understanding the possible cross-sectorial impacts of climate change and implementing reliable adaptation measures are key issues in Tainan City. The objective of this study is to apply a systematic assessment framework under Taiwan Water Resources Assessment Program to Climate Change (TaiWAP) (Liu et al. 2009; Tung et al. 2014) and grading indicators to assess the cross-sectorial vulnerability and resilience in Tainan City under climate change. Different adaption measures are then adopted to evaluate their effects on reducing vulnerability and promoting resilience. Procedures proposed in this study can be applied to support decision making for adaption measures for water resources management under changing climate.

\section{STUDY AREA}

\subsection{Zenwen River Watershed}

The study area is the Zenwen River watershed, which flows through Southern Taiwan and provides major water resources for the City of Tainan. The upstream tributaries of the Zenwen River include the Houku River and Tsai-Liao River, as shown in Fig. 1. Overviews of each tributary are as follows.

\section{(1) Zenwen River upstream}

The Zenwen River upstream drainage area is $481 \mathrm{~km}^{2}$. Nine precipitation stations (Zenwen, Shuishan, Leye, Lijia, Biaohu, Matoushan, Longmei, Sanjiaonanshan, and Dadongshan), 1 weather station (Tainan), and 1 discharge station (Zenwen reservoir) were selected for analysis. Annual precipitation and discharge are about 2958 and $2309 \mathrm{~mm}$, respectively.

\section{(2) Houku River}

The Houku River drainage area is $104 \mathrm{~km}^{2}$. Three precipitation stations (Sanjiaonanshan, Guanshan, and Sialiguan), 1 weather station (Tainan), and 1 discharge station (Nanhua reservoir) were selected for analysis. The annual precipitation and discharge are about 2951 and $2056 \mathrm{~mm}$, respectively.

\section{(3) Tsai-Liao River}

The Tsai-Liao River drainage area is $121.3 \mathrm{~km}^{2}$. Three precipitation stations (Muzha, Qiding, and Hutoupi), 1 weather station (Tainan), and 1 discharge station (Tso-Chen)

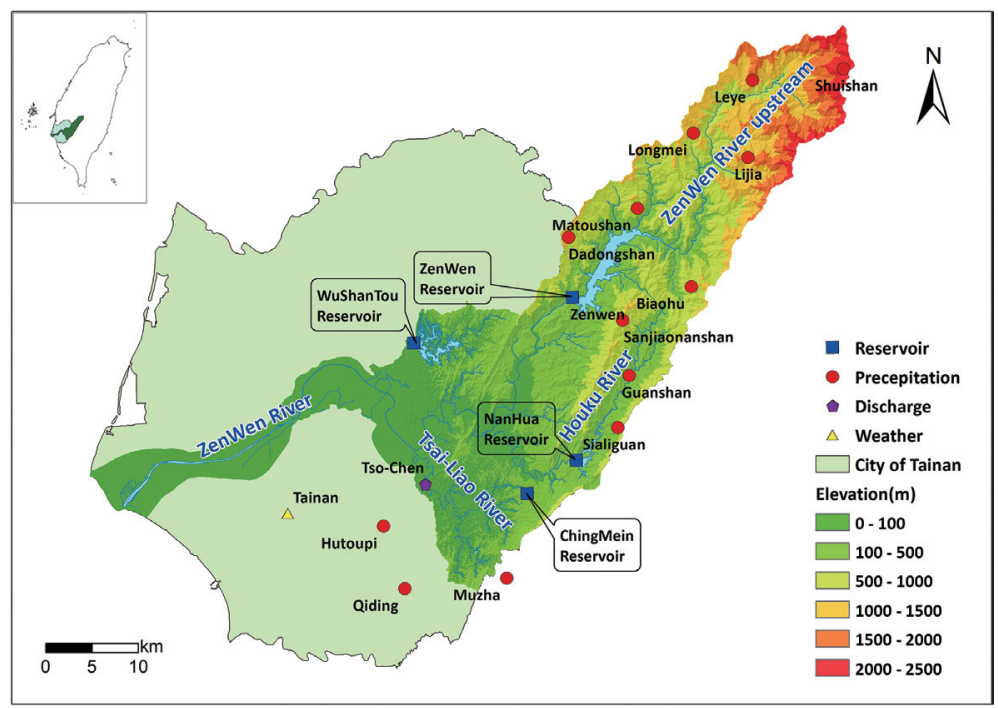

Fig. 1. The Zenwen River watershed shown with precipitation, weather and discharge stations used in this study. (Color online only) 
were selected for analysis. The annual precipitation and discharge are about 2263 and $1522 \mathrm{~mm}$, respectively.

\subsection{Water Supply System}

A schematic diagram of Tainan's water supply system is shown in Fig. 2. Figure 3 shows the main water supply facilities locations in Tainan. The major storage facilities in Tainan include the Zenwen reservoir, Wushantou reservoir, Nanhua reservoir, and Chingmein reservoir. The Zenwen reservoir, located upstream Zenwen River with a capacity of $4.7 \times 10^{8} \mathrm{~m}^{3}$ provides domestic, industrial and agriculture water. The Wushantou reservoir is located in midstream Zenwen River with a capacity of $8 \times 10^{7} \mathrm{~m}^{3}$ intakes water from the Zenwen reservoir mainly for agriculture. The Nanhua reservoir is located in the Houku River, with a capacity of $9.8 \times 10^{7} \mathrm{~m}^{3}$, provides domestic and industrial water. The Chingmein reservoir is located in the Cailiao River with a capacity of $10^{6} \mathrm{~m}^{3}$ provides domestic water.

There are five water treatment plants (Tanding, Wushantou, Nanhua, Chingmein, and Nanyu) in Tainan City. The Tanding water treatment plant with a capacity of $1.8 \times 10^{5}$ CMD withdraws water from the Zenwen reservoir. The Wushantou water treatment plant with a capacity of $2.4 \times 10^{5} \mathrm{CMD}$ withdraws water from the Wushantou reservoir. The Nanyu water treatment plant with a capacity of $8.7 \times 10^{4} \mathrm{CMD}$ withdraws water from the Zenwen reservoir. The Nanhua water treatment plant with a capacity of $6.5 \times 10^{5} \mathrm{CMD}$ withdraws water from the Nanhua reservoir. The Chingmein water treatment plant with a capacity of $4.5 \times 10^{4} \mathrm{CMD}$ withdraws water from the Chingmein reservoir. Table 1 lists the water supply facilities with their capacity and purpose in Tainan.

\section{METHODOLOGY}

\subsection{Climate Change Impact Assessment Procedure for Water Resources}

We applied TaiWAP, which integrates a weather generator, a hydrological model, and water resources system dynamic models, to assess the cross-sectorial vulnerability and resilience under climate change. The assessment procedure is described below, and shown in Fig. 4.

\section{(1) Climate change scenarios and downscaling}

Climate change projections require the results of General Circulation Models (GCMs) and future climate scenarios. However, the GCM spatial resolution is too coarse and should be downscaled to local-scale to resolve the local climate characteristics in Taiwan. The GCM results after downscaling are provided by the Taiwan Climate Change Projection and Information Platform Project (TCCIP). IPCC defined the Representative Concentration Pathways (RCPs) by their approximate total radiative forcing in the year 2100 relative to 1850 . Four RCPs include one mitigation scenario leading to a very low forcing level (RCP2.6), two stabilization scenarios (RCP4.5 and RCP6.0) and one scenario with very high greenhouse gas emissions (RCP8.5) (IPCC 2013).

\section{(2) Weather generator}

The weather generator (Tung and Haith 1995) was adopted to generate daily baseline temperature and precipitation and different climate scenarios for hydrological model input. Weather data realizations were generated based on observation data statistical characteristics and the differences in temperature and the ratio in precipitation, with respect to the baseline climatology, projected by GCMs. The daily temperature is generated using first-order Markov chains. The daily precipitation is generated in two steps. First, the conditional probability is considered to derive the occurrence of precipitation; second, the amount is generated by considering an exponential distribution.

\section{(3) Hydrological model}

The Generalized Watershed Loading Function (GWLF; Haith et al. 1992) is used in this study to simulate the runoff as the input for the System Dynamic Model (SDM). The GWLF water balance concept is shown in Fig. 5. The ground aquifer is divided into unsaturated, shallow saturated, and confined aquifer zones. When rainfall occurs, some rain infiltrates the soil and the other part flows directly into the rivers, called direct runoff $(\mathrm{Q})$, while evapotranspiration might return some of the water from the land back into the atmosphere. When the unsaturated zone water exceeds field capacity, the water will percolate into shallow saturated zones and then finally flow in the form of groundwater flow

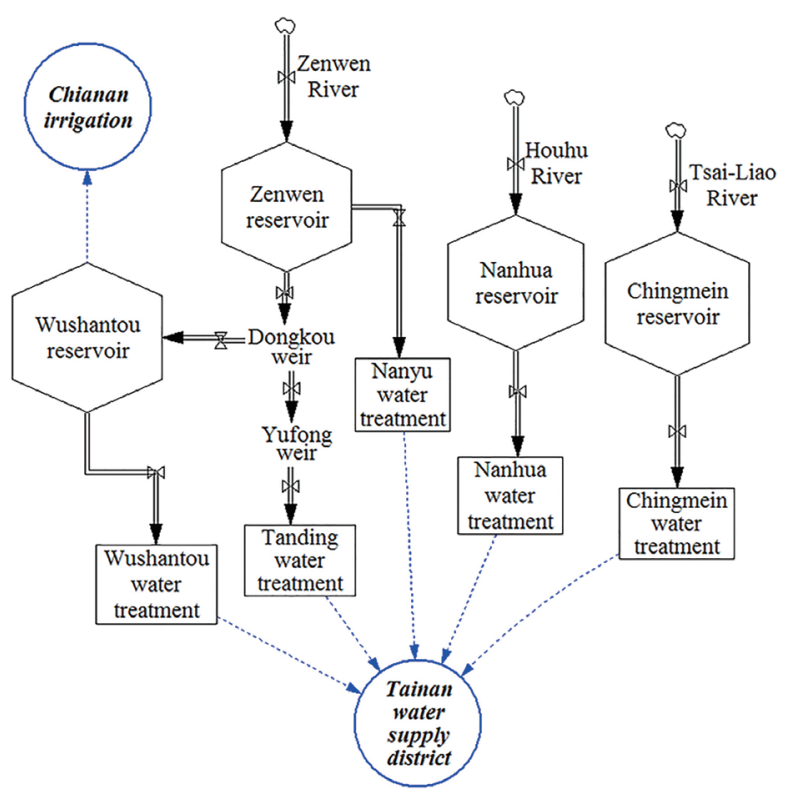

Fig. 2. Tainan's water supply system. (Color online only) 


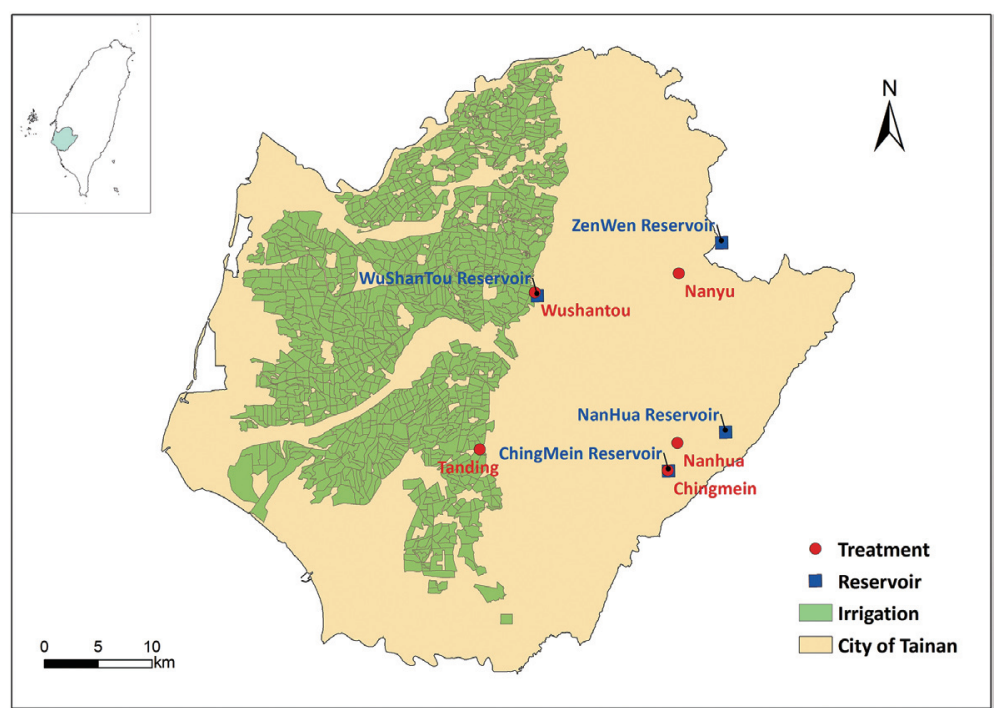

Fig. 3. The major water resources facilities in Tainan. (Color online only)

Table 1. Capacity and usage purpose of major reservoirs with corresponding water treatment plans in Tainan City.

\begin{tabular}{c|c|c|c}
\hline Reservoir & Capacity/Available water storage $\left(\mathbf{1 0}^{\mathbf{4}} \mathbf{m}^{\mathbf{3}}\right)$ & Purpose & Water treatment plant/Capacity $\mathbf{( 1 0 ^ { 4 }} \mathbf{C M D )}$ \\
\hline \multirow{2}{*}{ Zenwen } & $47955 / 47330$ & domestic, industrial and agriculture & Tanding/18 \\
\cline { 3 - 4 } & $8376 / 7982$ & agriculture and domestic & Nanyu/8.7 \\
\hline Wushantou & $9943 / 9793$ & domestic and industrial & Wushantou/24 \\
\hline Nanhua & $120 / 103$ & domestic & Nanhua/65 \\
\hline Chingmein & \multirow{2}{*}{ Chy } & & Chingmein/4.5 \\
\hline
\end{tabular}

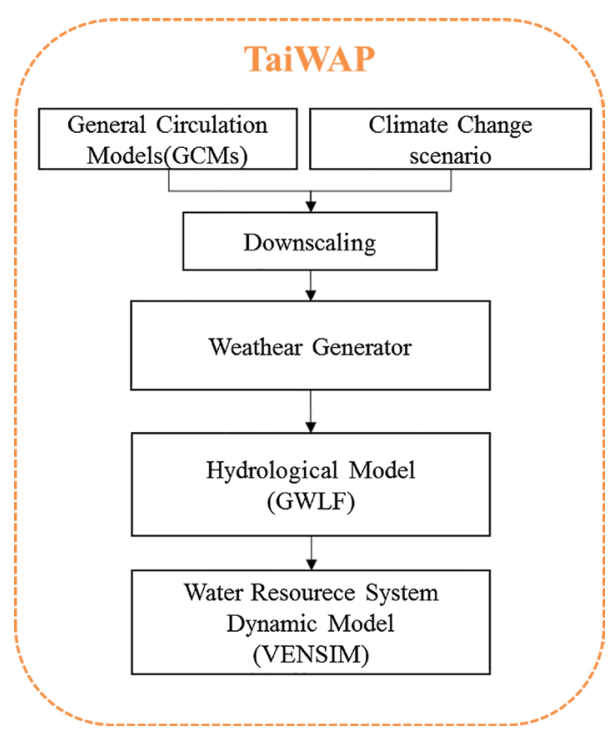

Fig. 4. Flowchart of climate change impact assessment on water resources. (Color online only) 


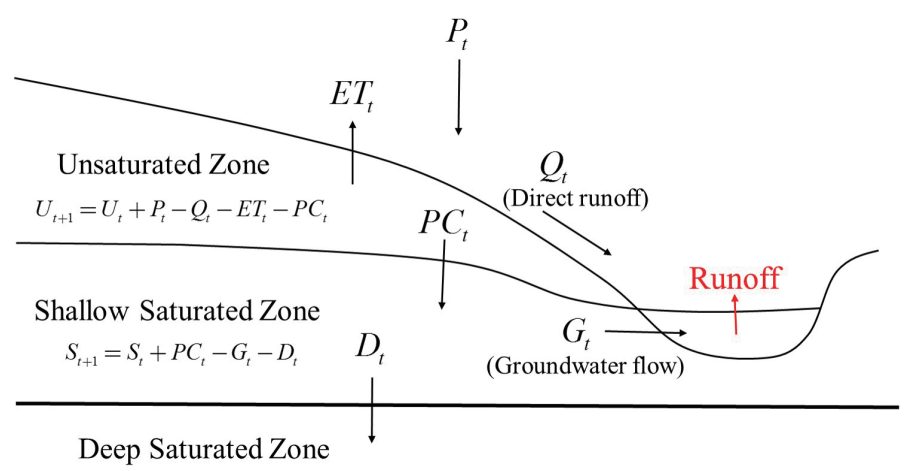

Fig. 5. Schematic diagram of the GWLF hydrological model. (Color online only)

(G) into rivers. Precipitation and evapotranspiration comprise meteorological forcing, and the output includes direct runoff and groundwater flow, whereby the difference in runoff between the baseline and climate change can be estimated and impact assessment can be further carried out.

\section{(4) Water resources SDM}

The available water supply is not simply equivalent to the river flow, reservoir capacity, or sum of water treatment plants' capacity. Instead, it should consider all components in a water resources system, like inflow, effective reservoir capacity, the operation rules and water demand, which includes domestic, industrial and agriculture usage. A water resources SDM for Tainan was built in this study through Vensim (Ventana 2007), using GWLF output and different water demand purposes to simulate the available water. The water supply system impact under climate change can be evaluated by SDM, and adaptation measures can be further proposed to evaluate the changes between the water supply and demand, as well as the risk for drought. The vulnerability and resilience of water resources can then finally be assessed.

\subsection{Definition of Assessing Indicators}

Vulnerability and resilience serve as the assessment indicators in this study. The concept of resilience, Time to Failure (TTF) and Time to Repair (TTR) were frequently used in industrial engineering and management to evaluate the reliability of hardware or a system. Figure 6 illustrates TTF and TTR in a water supply system with a temporal scale of 10 days for each grid in the horizontal axis. The green grid, TTF, means the duration of successful water supply. The red grid, TTR, means the duration of water shortage. For example, there are 4 TTF events $(30,60,20,10$ days) and 4 TTR events (40, 30, 10, 20 days) illustrated in Fig. 6. The resilience and availability indicators in water resources are based on evaluating the variation in duration between supply (carry capacity) and demand (loading) under the impact of climate change. The vulnerability indicators are defined to evaluate the severity of water shortages. The definitions of 5 indicators are described below and Table 2 lists the case results in Fig. 6. Figure 7 shows the flowchart for the indicators calculation.

\section{(1) Vulnerability indicator 1}

Vulnerability indicator 1 is used to represent the maximum total cumulative deficit among all water shortage events. The water shortage for public water is estimated using the Deficit Percent Day (DPD) having a unit of \%-day. The DPD was proposed by the Water Resources Development Public Corp. in 1977, which calculates the accumulated shortage percentage. Therefore, vulnerability indicator 1 will be the largest accumulated DPD among all shortage events. The formula is listed as below:

$\mathrm{DPD}_{M a x}=\operatorname{Max}\left[\sum_{i=1}^{N}\left(1-\frac{S_{i}}{D_{i}}\right) \times 100\right]$

where $N$ is the number of time steps that the supply cannot meet demand in a shortage event; $D_{i}$ is the water demand in a time step; $S_{i}$ is the water supply in a time step. For the example shown in Fig. 6, red grids mean the system is failure and each red grid represents $10 \%$ of water shortage. As a result, the first failure event has duration of 40 days and a DPD of $800 \%$. For the case in Fig. 6, the vulnerability indicator 1 is 1200 (\%-day).

Likewise, the water shortage on the paddy growing process may have cumulative impact, which will finally be reflected in crop yield. The total agricultural water deficit $\left(T D_{A g}\right)$ in one crop season is defined as vulnerability indicator 1 for agriculture water using the formula:

$T D_{A g}=\frac{\sum_{i=1}^{n}\left(D_{i}-S_{i}\right)}{\sum_{i=1}^{n} D_{i}} \times 100$, when $D_{i}>S_{i}$

where $n$ is the number of time steps in one crop season. In Tainan, the first crop is from February to May; the second crop is from July to October; $D_{i}$ is the water demand in a time 
step; $S_{i}$ is the water supply in a time step; the vulnerability indicator 1 for agricultural water $\left(T D_{A g}\right)$ is dimensionless.

\section{(2) Vulnerability indicator 2}

This indicator means the maximum deficit in a time step among all water shortage events. It can gauge the potential extreme shortage in a water resources system. The unit of vulnerability indicator 2 is the same as vulnerability indicator 1. For the case in Fig. 6, the vulnerability indicator 2 is 600 (\%-day).

\section{(3) Resilience indicator 1}

Mean Time to Repair (MTTR) indicates the average failure duration in system operation; the smaller the MTTR, the faster the system can repair. For the case in Fig. 6, the resilience indicator 1 is 25 (days).

\section{(4) Resilience indicator 2}

This indicator is defined as the maximum TTR among all water shortage events. The bigger the TTR the longer the failure duration is. Resilience indicator 2 and vulnerability indicator $1 \mathrm{can}$ be considered as the system potential impact. For the case in Fig. 6, the resilience indicator 2 is 40 (days).

\section{(5) Availability indicator}

The availability indicator indicates the mean duration

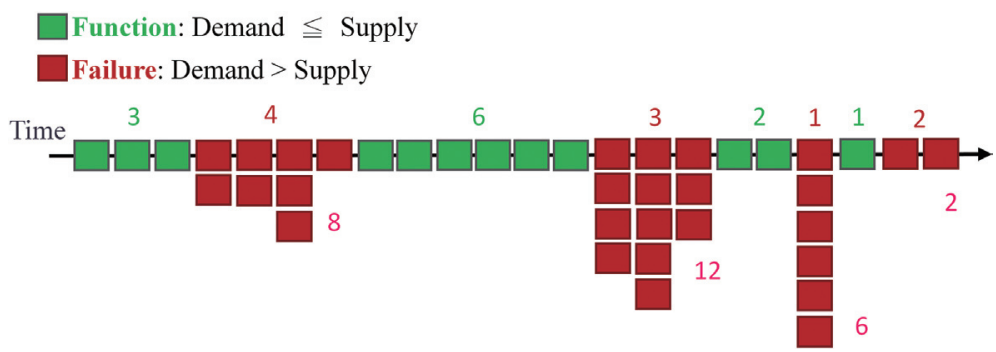

Fig. 6. An example of functioned (green grids) and failed (red grids) water resources system. Each grid represents 10 days in time scale. A functioned system means supply is greater than demand, while a failed system is demand larger than supply. Each red grid denotes $10 \%$ of shortage. (Color online only)

Table 2. Values of assessment indicators calculated with the example given in Fig. 6.

\begin{tabular}{c|c|c}
\hline Indicators & Definition & Case \\
\hline Resilience indicator 1 & Mean Time To Repair (MTTR) & Average $(40,30,10,20)=25($ days $)$ \\
\hline Resilience indicator 2 & Max. TTR & Max $(40,30,10,20)=40($ days $)$ \\
\hline Availability indicator & MTTF/(MTTR + MTTF) & $100 \times[$ Average $(30+60+20+10)] /(25+30)=54.5(\%)$ \\
\hline Vulnerability indicator 1 & Max. cumulative DPD among all shortage events & Max $(800,1200,600,200)=1200(\%$-day) \\
\hline Vulnerability indicator 2 & Max. DPD in a time step & $600(\%$-day) \\
\hline
\end{tabular}

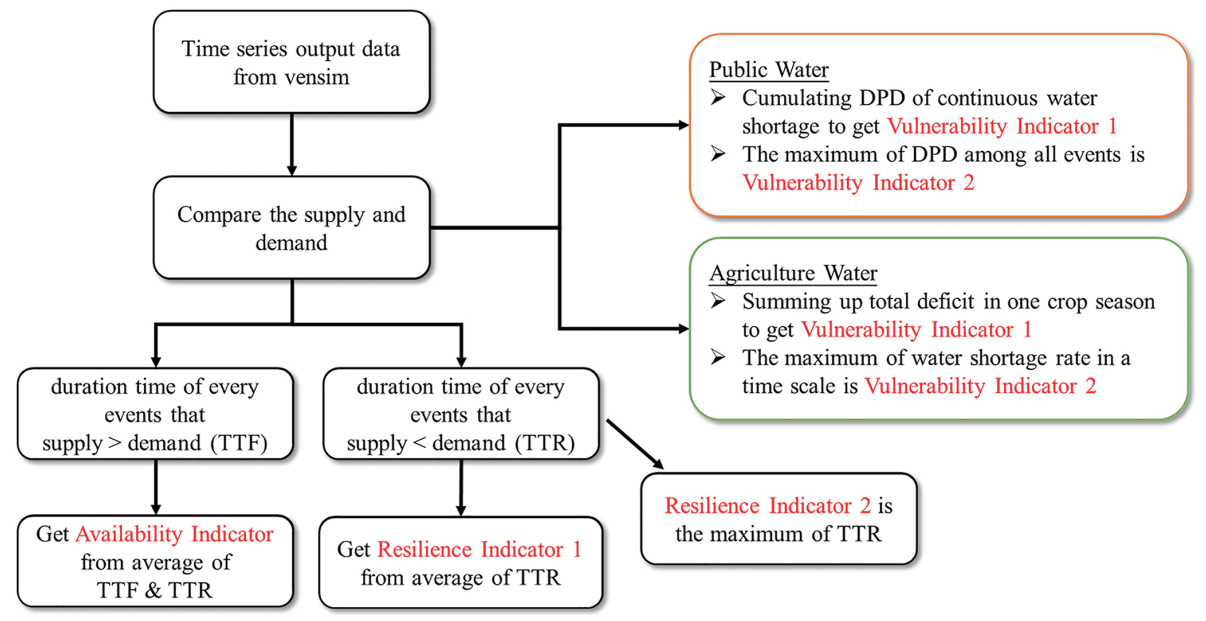

Fig. 7. Flowchart of calculating the assessing indicators. (Color online only) 
of no water shortage in system operation. It can be estimated by MTTF/(MTTF + MTTR), where MTTF (Mean Time to Failure) means the average functional duration. For the case in Fig. 6, the availability indicator is $54.5(\%)$.

\subsection{Water Demand in a Water Resources SDM}

The SDM water resources needs input data contain river runoff and total water demand. Water supply is determined according to the inflow, capacity of reservoirs or water treatment plants, the operation rules and water demand. The total water demand includes agriculture and public. The public water demand is the total water demand from both domestic and industrial sectors. Agricultural water demand is provided by the Taiwan Agriculture Research Institute (TARI) with the Decision Support System for Agrotechnology Transfer (DSST; Jones et al. 2003) software. The DSSAT crop simulation models are used to simulate growth, development, and yield as a function of the soil-plant-atmosphere dynamics to provide agricultural water demand estimations in crop seasons. Domestic water demand $(D W D)$ is estimated by population $(P L)$, average domestic water consumption per capita per day (liters per capita per day, $L P C D)$, prevalence rate $(P R)$, and deficit rate (DR) (WRA 2009) as follows,

$$
D W D=\frac{P L \times L P C D \times P R}{D R}
$$

Industrial water demand is estimated according to the water consumption plan of the Industry Park submitted to the Water Resources Agency. Figure 8 shows the baseline water demand for Tainan.

Two scenarios are considered in this study to estimate future water demand, as shown in Table 3.

(1) Future water demand scenario (I): In view of assessing the water resources vulnerability caused only by climate change, the variation in public water demand is ignored, i.e., future public water demand remains the same as the baseline.

(2) Future water demand scenario (II): In view of assessing the water resources vulnerability affected by both climate change and socio-economic development, the variation in agriculture and public water demand is considered.

\subsection{Grading Assessment Indicators}

There are 4 steps to grade the assessment indicators. The first step is to use historical weather data (1980 - 2009) as the hydrological model input and following the climate change impact assessment procedure for water resources. The second step is to obtain the time series for indicators according to the definition described above. The third step is to arrange the indicators in descending order to obtain the exceedance probabilities via the following equation:

$\operatorname{CDF}(\%)=\frac{\text { rank }}{(1+\mathrm{N})}$

where $\mathrm{CDF}(\%)$ is the exceedance probabilities; rank is the order after descending; $\mathrm{N}$ is the total number of data years. In this study, data years from 1980 to 2009 were used for grading assessment which makes $\mathrm{N}=30$. The exceedance probability of the first order indicator is $[1 /(1+30)]=3.23 \%$. Finally, each indicator provides 3 grades (low, medium, and high) defined by two thresholds using 30 and $70 \%$ exceedance probabilities, as described below:

\section{(1) Low}

The exceedance probability of an indicator greater than $70 \%$ belongs to low grade, i.e., $70 \%<\mathrm{CDF} \leq 100 \%$, indicating relatively low impact upon the water resources system. Moreover, the system has a stable water supply.

\section{(2) Medium}

The exceedance probability of an indicator between 30 and $70 \%$ belongs to medium grade, i.e., $30 \%<\mathrm{CDF} \leq$ $70 \%$, indicating a medium impact upon the water resources system. Moreover, there may be more water shortage events in the system; therefore, closely monitoring the change between supply and demand is necessary.

\section{(3) High}

The exceedance probability of an indicator smaller than $30 \%$ belongs to high grade, i.e., $0 \%<\mathrm{CDF} \leq 30 \%$, indicating a relatively high impact upon the water resources system. Moreover, the system is overloaded; therefore, adaptation measures need to be implemented as soon as possible.

The exceedance probabilities and two thresholds of vulnerability 1 for public water are illustrated in Fig. 9 as an example. The indicator corresponding to exceedance probability of $70 \%$ is 200 (\%-day), i.e., the low grade threshold. The indicator corresponding to exceedance probability of $30 \%$ is 900 (\%-day), i.e., the medium grade threshold. Tables 4 and 5 list the grading thresholds for 5 public and agriculture water indicators, respectively. Climate change impact assessment results were averaged and compared with the thresholds to determine the grade. According to the indicator definitions and our grading approaches, vulnerability indicator 1 , vulnerability indicator 2 , resilience indicator 1 , and resilience indicator 2 in low values are favorable to water resources, while the availability indictor is opposite.

\section{RESULTS}

\subsection{Climate Change Scenarios}

A total of 3 GCMs, 2 RCPs, and 2 time periods were 


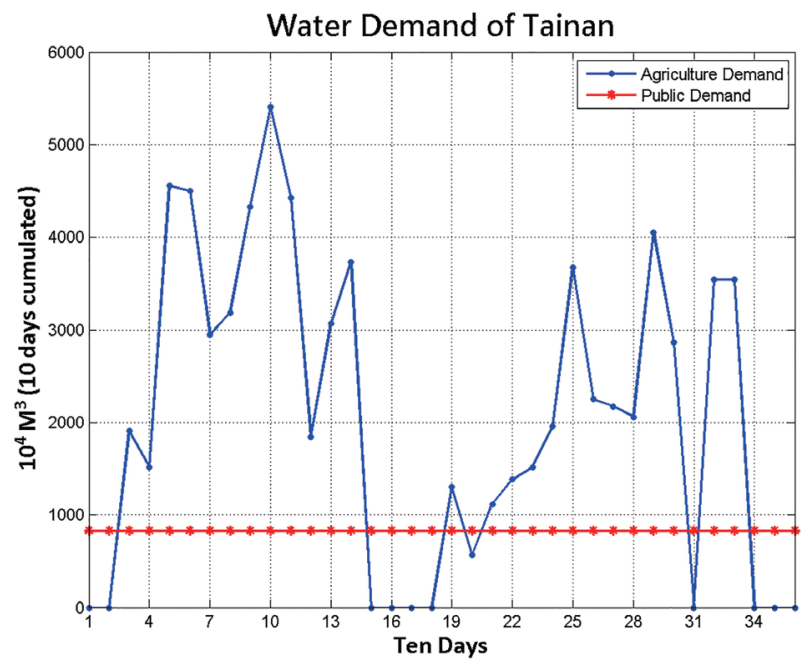

Fig. 8. Public water demand and agriculture water demand in Tainan. (Color online only)

Table 3. Future water demand scenarios setting.

\begin{tabular}{c|c|c}
\hline & Setting & Purpose \\
\hline Future water demand scenario (I) & $\begin{array}{c}\text { Climate Change (variation of public water } \\
\text { demand is ignored) }\end{array}$ & $\begin{array}{c}\text { Vulnerability of water resources only caused by climate change } \\
\text { (variation of discharge and agriculture water demand are considered) }\end{array}$ \\
\hline Future water demand scenario (II) & $\begin{array}{c}\text { Climate Change (variation of public and } \\
\text { agriculture water demand are considered ) }\end{array}$ & $\begin{array}{c}\text { Vulnerability of water resources caused by both climate change and } \\
\text { socio-economic development (variation of discharge and total water } \\
\text { demand are considered) }\end{array}$ \\
\hline
\end{tabular}

\section{PUBLIC WATER-VULNERABILITY INDICATOR 1}

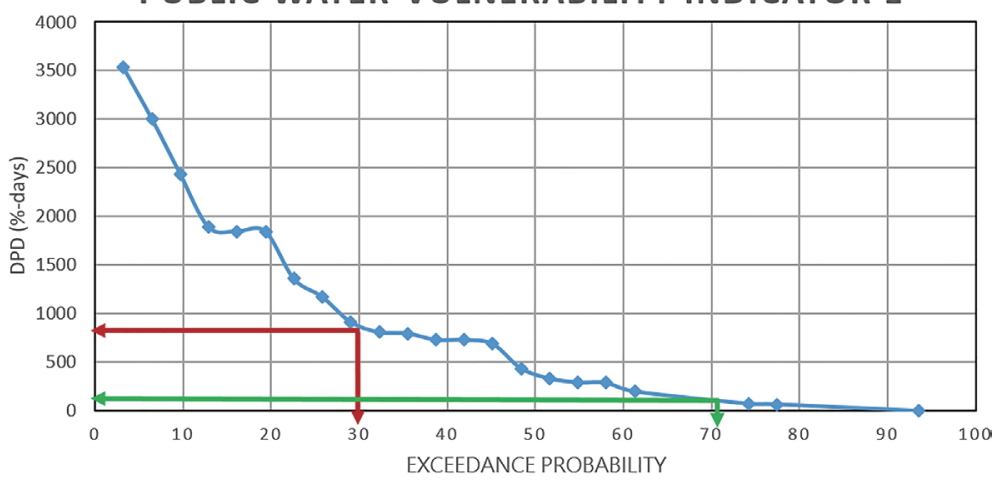

Fig. 9. Exceedance probabilities of vulnerability indicator 1 for public water. The green and red lines indicate thresholds of low and high grades with 70 and $30 \%$ exceedance probabilities, respectively. (Color online only)

Table 4. Grading thresholds of public water.

\begin{tabular}{c|c|c|c|c|c}
\hline & Vulnerability indicator 1 & Vulnerability indicator 2 & Resilience indicator 1 & Resilience indicator 2 & Availability indicator \\
\hline $\begin{array}{c}\text { Threshold between } \\
\text { low and medium grade }\end{array}$ & $200(\%$-day) & $5(\%$-day) & 20 (days) & $25($ days $)$ & $85(\%)$ \\
\hline $\begin{array}{c}\text { Threshold between } \\
\text { medium and high } \\
\text { grade }\end{array}$ & $900(\%$-day) & $30(\%$-day) & 80 (days) & 115 (days) & $60(\%)$ \\
\hline
\end{tabular}


Table 5. Grading thresholds of agriculture water.

\begin{tabular}{c|c|c|c|c|c}
\hline & Vulnerability indicator 1 & Vulnerability indicator 2 & Resilience indicator 1 & Resilience indicator 2 & Availability indicator \\
\hline $\begin{array}{c}\text { Threshold between } \\
\text { low and medium grade }\end{array}$ & $25(\%)$ & $55(\%)$ & 55 (days) & $80($ days $)$ & $60(\%)$ \\
\hline $\begin{array}{c}\text { Threshold between } \\
\text { medium and high } \\
\text { grade }\end{array}$ & $40(\%)$ & $65(\%)$ & $80($ days $)$ & $115($ days $)$ & $(\%)$ \\
\hline
\end{tabular}

chosen to assess climate change impact on water resources in Tainan City as shown in Table 6. The variation in discharge between wet and dry seasons is shown in Figs. 10 - 12. The CESM1-CAM5 (i.e., Community Earth System Model version 1 includes Community Atmospheric Model version 5) results show a tendency for increased discharge during the wet season but decreased discharge during the dry season. The GFDL-CM3 (i.e., Geophysical Fluid Dynamics Laboratory Climate Model version 3) results show a tendency for increased discharge; instead, the HadGEM2-AO (i.e., Hadley Center Global Environment Model version 2 with fullycoupled atmosphere-ocean version) results show a tendency for decreased discharge.

Public water demand in the baseline and the future are listed in Table 7. The industrial water demand under RCP2.6 and RCP8.5 corresponds to low and rapid economic development, respectively. We did not consider variations in domestic water demand due to climate change. The increment between the baseline and the future results mostly from industrial water demand growth. Table 8 shows the amount of agriculture water demand provided by the TARI in baseline and different scenarios. Figure 13 shows the variation in agriculture water demand between the baseline and different scenarios. All of the results show a tendency for increased demand; in addition, RCP8.5 over a long period has the greatest increment.

\subsection{Variation in Vulnerability and Resilience Between the Baseline and Projected Future}

Assessment indicator results under future water demand scenario (I) are listed in Table 9. In the baseline, all assessment indicators are in low vulnerability, low resilience, and high availability. This indicates that the water resource system in Tainan may experience relatively low impact and can offer a steady water supply. As described in 4.1, different GCMs predict different discharge variations, which lead to different assessment results. The assessment indicator results in GFDL-CM3 are expected to be the same as those in the baseline because the projected discharges in wet and dry seasons will both increase, as shown in Fig. 11. On the other hand, assessment indicator results in both CESM1-CAM5 and HadGEM2-AO are likely to get worse due to the projected discharges in the dry season will decrease, meaning less available water, as shown in Figs. 10 and 12. Especially un- der the RCP8.5 scenario in 2100 , the results show that there might be more water shortage events and longer failure durations than the baseline, in Tainan's water resources system.

Table 10 lists the assessment indicator results under future water demand scenario (II). Considering the significant increase in public water demand, the public water assessment indicators will have high vulnerability, high resilience, and low availability, caused by insufficient water supply facilities capacity. The CESM1-CAM5 and HadGEM2-AO results show agriculture water supply failure duration will be longer and the resilience indicators will be mediumgrade, particularly under the RCP8.5 scenario in 2100; vulnerability indicator 2 will also be in medium grade.

In spite of different climate change scenarios, the previous results show more agriculture water shortages and extreme public water shortages under the stress of expanded future public water demand. According to the above statement, the water resources management concerns in Tainan will mainly involve the following:

(1) Wide temporal precipitation distribution is a great challenge to water resources management.

(2) Rapid economic, industrial developments and population growth enhance stress on future water supply.

(3) Insufficient water supply facilities capacity causes low resilience in drought conditions.

(4) Limitations to properly allocating water resources due to agriculture water needs accounts for a huge part of total water usage.

\subsection{Adaptation Measures Effects Against the Impacts of Climate Change}

\subsubsection{Applicability of Cross-Space Adaptation Measures}

This study assesses the potential effects of adaptation measures and aims to identify the applicability of adaptation technology in different planning spatial areas, as shown in Fig. 14. Nine adaptation measures were examined with water resources SDM to evaluate indicator variations after implementing different adaption measures. Table 11 lists 9 adaptation measures with their corresponding planning spatial scale and implementation contents. Where (a) desalination, (b) water treatment plant expansion, (c) construction of water supply facilities, and (d) construction of reservoir are mainly supply public water. Where (e) artificial lake is 
a multi-objective artificial lake that can supply both agriculture and public water. Where (f) promoting water conservation to reduce the amount of public water; and then $(\mathrm{g})$ agriculture water conservation, (h) adjustment of cropping system, and (i) reducing leakage rate are based on reducing agriculture water demand.

\subsubsection{Outcomes of Implementing Adaptation Measures}

Future water demand scenario (II) over a long period represents a great increase in both public and agricultural water demands, which is likely to link with RCP8.5 over a long period. Projections of Had2GEM-AO with RCP8.5 over a long period show the increase in annual discharges are much less than those of CESM1-CAM5, meaning less available water, as shown in Figs. 10 and 12. Therefore, Had2GEM-AO with RCP8.5 over a long period was chosen to assess the implementation of different and combined adaption measures. Variations in assessment indicators after implementing adaptation measures are shown in Table 12. Because the rapid growth of public water demand is considered, the water supply cannot meet water demand. The water shortage will be about $30 \%$ during the dry season and $10 \%$ during the wet season. All adaptation measures will be unable to satisfy such increments if implemented alone. Although the water shortage rate will decrease, the assessment indicators for public water will still exhibit high vulnerability, high resilience and low availability. The adaptation, including (e), (g), (h), and (i) are in connection with agriculture water. Agriculture water demand will also increase under climate change scenarios and the outcomes of implementing (e) are not obvious. Implementing (g) will cause long failure duration and the assessment indicators for agriculture water will be in high resilience and medium availability. Implementing (h) significantly reduces agriculture water demand; consequently, the assessment indicators for agriculture water will become the same as the baseline. Although $(\mathrm{g})$ and $(\mathrm{h})$ could greatly reduce the amount of water demand, they could cause reduced crop yields. As for implementing (i) to improve water resources usage, the assessment indicators will be in low vulnerability.

Due to no improvement in public water after implementing individual adaptation measures, the combination of adaptation measures will be adopted as follows. After implementing the combination of (a), (f), and (h), the water shortage rate of public water will decrease to about $15 \%$ during

Table 6. Climate scenarios adopted in this study.

\begin{tabular}{c|c|c}
\hline GCMs & Scenarios & Time periods \\
\hline CESM1-CAM5 & RCP2.6 & Short term $(2021-2040)$ \\
GFDL-CM3 & RCP8.5 & Long term $(2081-2100)$ \\
HadGEM2-AO & & \\
\hline
\end{tabular}

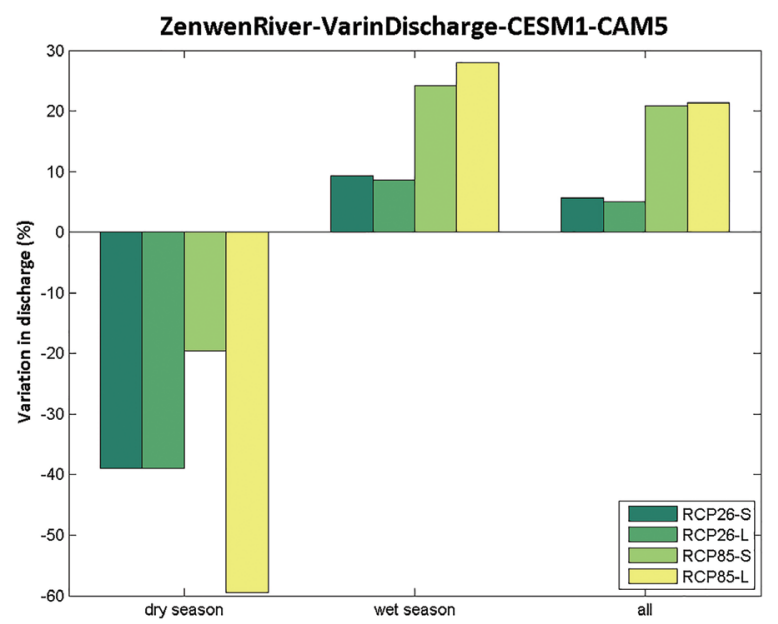

Fig. 10. Discharge variations in wet and dry seasons with CESM1CAM5. (Color online only)

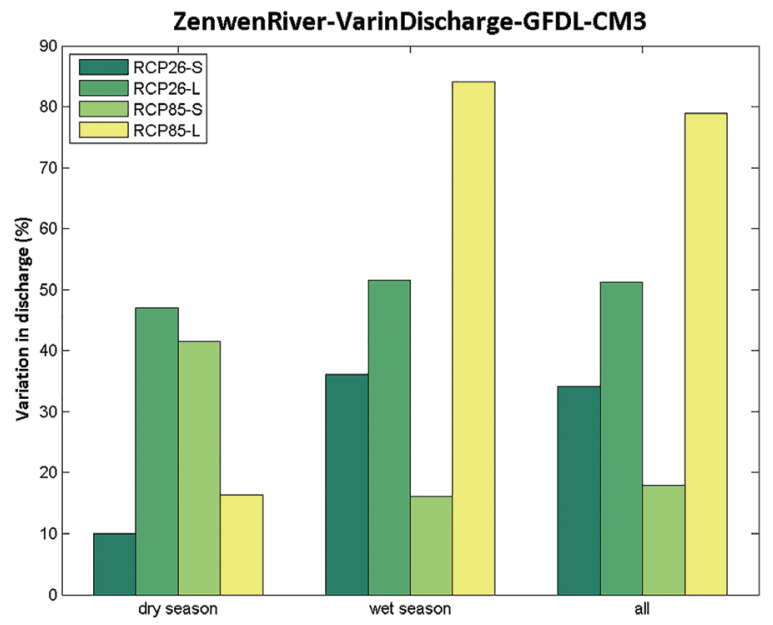

Fig. 11. Discharge variations in wet and dry seasons with GFDL-CM3 (Color online only)

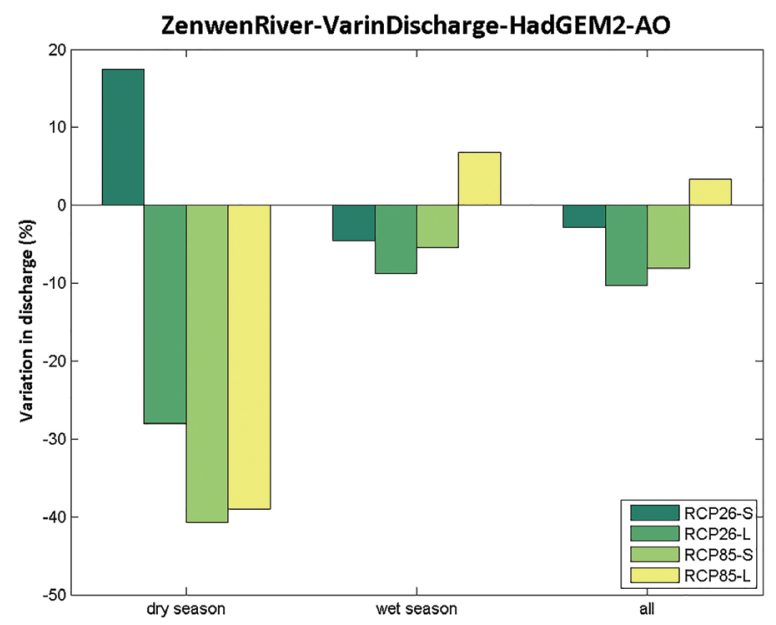

Fig. 12. Discharge variations in wet and dry seasons with HadGEM2AO. (Color online only) 
Table 7. Public water demand in baseline and future (unit: $10^{4} \mathrm{CMD}$ ).

\begin{tabular}{c|c|c|c}
\hline & Baseline & RCP2.6 (Low growth) & RCP8.5 (Rapid growth) \\
\hline Domestic Water & 63.6 & 67 & 67 \\
\hline Industrial Water & 19.5 & 38.9 & 51.2 \\
\hline Public Water (Total) & 83.1 & 105.9 & 118.2 \\
\hline Increment & - & 22.8 & 35.1 \\
\hline
\end{tabular}

Table 8. Agriculture water demand in baseline and future (unit: $\left.10^{4} \mathrm{CMD}\right)$.

\begin{tabular}{|c|c|c|c|}
\hline & & & Agriculture water demand \\
\hline \multicolumn{3}{|c|}{ Baseline } & 73425 \\
\hline \multirow{4}{*}{ CESM1-CAM5 } & \multirow{2}{*}{ RCP2.6 } & $\mathrm{S}$ & 74583 \\
\hline & & $\mathrm{L}$ & 75568 \\
\hline & \multirow{2}{*}{ RCP8.5 } & $\mathrm{S}$ & 74927 \\
\hline & & $\mathrm{L}$ & 78448 \\
\hline \multirow{4}{*}{ GFDL-CM3 } & \multirow{2}{*}{ RCP2.6 } & $\mathrm{S}$ & 75082 \\
\hline & & $\mathrm{L}$ & 75781 \\
\hline & \multirow{2}{*}{ RCP8.5 } & $\mathrm{S}$ & 75177 \\
\hline & & $\mathrm{L}$ & 79016 \\
\hline \multirow{4}{*}{ HadGEM2-AO } & \multirow{2}{*}{ RCP2.6 } & $\mathrm{S}$ & 74598 \\
\hline & & $\mathrm{L}$ & 75091 \\
\hline & \multirow{2}{*}{ RCP8.5 } & $\mathrm{S}$ & 74815 \\
\hline & & $\mathrm{L}$ & 77698 \\
\hline
\end{tabular}

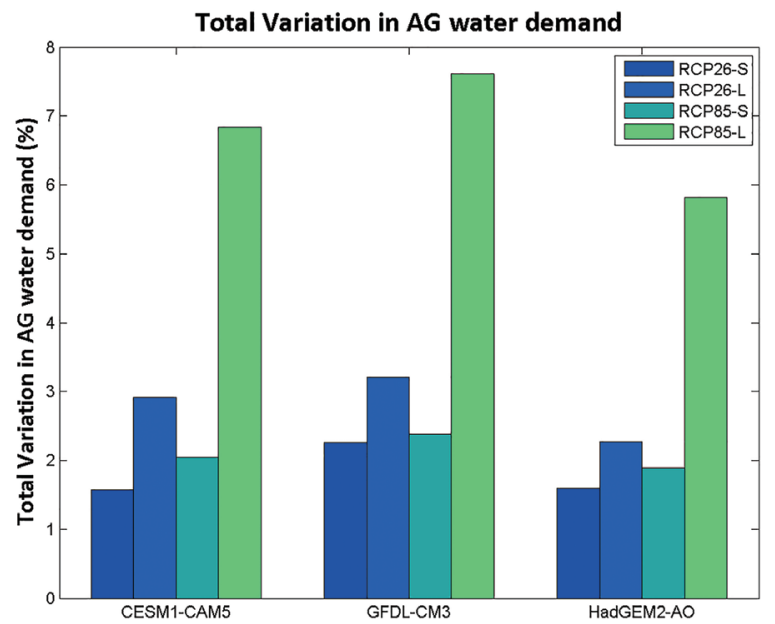

Fig. 13. Variations of agriculture water demand. (Color online only) 
Table 9. Results of assessment indicators with future water demand scenario (I): VUL1 is vulnerability indicator1, VUL2 is vulnerability indicator 2, RES1 is resilience indicator 1, RES2 is resilience indicator 2, and AVA is availability indicator.

\begin{tabular}{|c|c|c|c|c|c|c|c|c|c|c|c|}
\hline \multirow{2}{*}{ Climate Scenarios } & \multirow{2}{*}{ GCMs } & \multicolumn{5}{|c|}{ Public Water } & \multicolumn{5}{|c|}{ Agriculture Water } \\
\hline & & VUL1 & VUL2 & RES1 & RES2 & AVA & VUL1 & VUL2 & RES1 & RES2 & AVA \\
\hline \multicolumn{2}{|c|}{ Baseline } & $\mathrm{L}$ & $\mathrm{L}$ & $\mathrm{L}$ & $\mathrm{L}$ & $\mathrm{H}$ & $\mathrm{L}$ & $\mathrm{L}$ & $\mathrm{L}$ & $\mathrm{L}$ & $\mathrm{H}$ \\
\hline \multirow{3}{*}{ RCP2.6-S } & CESM1-CAM5 & $\mathrm{L}$ & $\mathrm{L}$ & $\mathrm{L}$ & $\mathrm{L}$ & $\mathrm{H}$ & $\mathrm{L}$ & $\mathrm{L}$ & $\mathrm{L}$ & $\mathrm{L}$ & $\mathrm{H}$ \\
\hline & GFDL-CM3 & $\mathrm{L}$ & $\mathrm{L}$ & $\mathrm{L}$ & $\mathrm{L}$ & $\mathrm{H}$ & $\mathrm{L}$ & $\mathrm{L}$ & $\mathrm{L}$ & $\mathrm{L}$ & $\mathrm{H}$ \\
\hline & HadGEM2-AO & $\mathrm{L}$ & $\mathrm{L}$ & $\mathrm{L}$ & $\mathrm{L}$ & $\mathrm{H}$ & $\mathrm{L}$ & $\mathrm{L}$ & $\mathrm{L}$ & $\mathrm{L}$ & $\mathrm{H}$ \\
\hline \multirow{3}{*}{ RCP2.6-L } & CESM1-CAM5 & $\mathrm{M}$ & $\mathrm{M}$ & $\mathrm{L}$ & $\mathrm{L}$ & $\mathrm{M}$ & $\mathrm{L}$ & $\mathrm{L}$ & $\mathrm{L}$ & $\mathrm{L}$ & $\mathrm{H}$ \\
\hline & GFDL-CM3 & $\mathrm{L}$ & $\mathrm{L}$ & $\mathrm{L}$ & $\mathrm{L}$ & $\mathrm{H}$ & $\mathrm{L}$ & $\mathrm{L}$ & $\mathrm{L}$ & $\mathrm{L}$ & $\mathrm{H}$ \\
\hline & HadGEM2-AO & $\mathrm{L}$ & $\mathrm{M}$ & $\mathrm{L}$ & $\mathrm{L}$ & $\mathrm{H}$ & $\mathrm{L}$ & $\mathrm{L}$ & $\mathrm{M}$ & $\mathrm{L}$ & $\mathrm{H}$ \\
\hline \multirow{3}{*}{ RCP8.5-S } & CESM1-CAM5 & $\mathrm{L}$ & $\mathrm{L}$ & $\mathrm{L}$ & $\mathrm{L}$ & $\mathrm{H}$ & $\mathrm{L}$ & $\mathrm{L}$ & $\mathrm{L}$ & $\mathrm{L}$ & $\mathrm{H}$ \\
\hline & GFDL-CM3 & $\mathrm{L}$ & $\mathrm{L}$ & $\mathrm{L}$ & $\mathrm{L}$ & $\mathrm{H}$ & $\mathrm{L}$ & $\mathrm{L}$ & $\mathrm{L}$ & $\mathrm{L}$ & $\mathrm{H}$ \\
\hline & HadGEM2-AO & $\mathrm{L}$ & $\mathrm{M}$ & $\mathrm{L}$ & $\mathrm{L}$ & $\mathrm{H}$ & $\mathrm{L}$ & $\mathrm{L}$ & $\mathrm{M}$ & $\mathrm{L}$ & $\mathrm{H}$ \\
\hline \multirow{3}{*}{ RCP8.5-L } & CESM1-CAM5 & $\mathrm{M}$ & $\mathrm{M}$ & $\mathrm{M}$ & $\mathrm{M}$ & M & $\mathrm{L}$ & $\mathrm{M}$ & $\mathrm{L}$ & $\mathrm{L}$ & $\mathrm{H}$ \\
\hline & GFDL-CM3 & $\mathrm{L}$ & $\mathrm{L}$ & $\mathrm{L}$ & $\mathrm{L}$ & $\mathrm{H}$ & $\mathrm{L}$ & $\mathrm{L}$ & $\mathrm{L}$ & $\mathrm{L}$ & $\mathrm{H}$ \\
\hline & HadGEM2-AO & M & M & $\mathrm{L}$ & $\mathrm{L}$ & $\mathrm{H}$ & $\mathrm{L}$ & $\mathrm{L}$ & $\mathrm{L}$ & $\mathrm{L}$ & $\mathrm{H}$ \\
\hline
\end{tabular}

Table 10. Results of assessment indicators with future water demand scenario (II): VUL1 is vulnerability indicator1, VUL2 is vulnerability indicator 2, RES1 is resilience indicator 1, RES2 is resilience indicator 2, and AVA is availability indicator.

\begin{tabular}{|c|c|c|c|c|c|c|c|c|c|c|c|}
\hline \multirow{2}{*}{ Climate Scenarios } & \multirow{2}{*}{ GCMs } & \multicolumn{5}{|c|}{ Public Water } & \multicolumn{5}{|c|}{ Agriculture Water } \\
\hline & & VUL1 & VUL2 & RES1 & RES2 & AVA & VUL1 & VUL2 & RES1 & RES2 & AVA \\
\hline \multicolumn{2}{|c|}{ Baseline } & $\mathrm{L}$ & $\mathrm{L}$ & $\mathrm{L}$ & $\mathrm{L}$ & $\mathrm{H}$ & $\mathrm{L}$ & $\mathrm{L}$ & $\mathrm{L}$ & $\mathrm{L}$ & $\mathrm{H}$ \\
\hline \multirow{3}{*}{ RCP2.6-S } & CESM1-CAM5 & $\mathrm{H}$ & $\mathrm{H}$ & $\mathrm{H}$ & $\mathrm{H}$ & $\mathrm{L}$ & $\mathrm{L}$ & $\mathrm{L}$ & $M$ & $\mathrm{~L}$ & $\mathrm{H}$ \\
\hline & GFDL-CM3 & $\mathrm{H}$ & $\mathrm{M}$ & $\mathrm{H}$ & $\mathrm{H}$ & $\mathrm{L}$ & $\mathrm{L}$ & $\mathrm{L}$ & $\mathrm{L}$ & $\mathrm{L}$ & $\mathrm{H}$ \\
\hline & HadGEM2-AO & $\mathrm{H}$ & $\mathrm{M}$ & $\mathrm{H}$ & $\mathrm{H}$ & $\mathrm{L}$ & $\mathrm{L}$ & $\mathrm{L}$ & M & $\mathrm{L}$ & $\mathrm{H}$ \\
\hline \multirow{3}{*}{ RCP2.6-L } & CESM1-CAM5 & $\mathrm{H}$ & $\mathrm{H}$ & $\mathrm{H}$ & $\mathrm{H}$ & $\mathrm{L}$ & $\mathrm{L}$ & $\mathrm{L}$ & $\mathrm{M}$ & $\mathrm{L}$ & $\mathrm{H}$ \\
\hline & GFDL-CM3 & $\mathrm{H}$ & $M$ & $\mathrm{H}$ & $\mathrm{H}$ & $\mathrm{L}$ & $\mathrm{L}$ & $\mathrm{L}$ & $\mathrm{L}$ & $\mathrm{L}$ & $\mathrm{H}$ \\
\hline & HadGEM2-AO & $\mathrm{H}$ & M & $\mathrm{H}$ & $\mathrm{H}$ & $\mathrm{L}$ & $\mathrm{L}$ & $\mathrm{L}$ & M & $\mathrm{L}$ & $\mathrm{H}$ \\
\hline \multirow{3}{*}{ RCP8.5-S } & CESM1-CAM5 & $\mathrm{H}$ & $\mathrm{H}$ & $\mathrm{H}$ & $\mathrm{H}$ & $\mathrm{L}$ & $\mathrm{L}$ & $\mathrm{L}$ & $\mathrm{L}$ & $\mathrm{L}$ & $\mathrm{H}$ \\
\hline & GFDL-CM3 & $\mathrm{H}$ & $\mathrm{H}$ & $\mathrm{H}$ & $\mathrm{H}$ & $\mathrm{L}$ & $\mathrm{L}$ & $\mathrm{L}$ & $\mathrm{L}$ & $\mathrm{L}$ & $\mathrm{H}$ \\
\hline & HadGEM2-AO & $\mathrm{H}$ & $\mathrm{H}$ & $\mathrm{H}$ & $\mathrm{H}$ & $\mathrm{L}$ & $\mathrm{L}$ & $\mathrm{L}$ & $M$ & $M$ & $\mathrm{H}$ \\
\hline \multirow{3}{*}{ RCP8.5-L } & CESM1-CAM5 & $\mathrm{H}$ & $\mathrm{H}$ & $\mathrm{H}$ & $\mathrm{H}$ & $\mathrm{L}$ & $\mathrm{L}$ & M & M & $\mathrm{L}$ & $\mathrm{H}$ \\
\hline & GFDL-CM3 & $\mathrm{H}$ & $\mathrm{H}$ & $\mathrm{H}$ & $\mathrm{H}$ & $\mathrm{L}$ & $\mathrm{L}$ & $\mathrm{L}$ & $\mathrm{L}$ & $\mathrm{L}$ & $\mathrm{H}$ \\
\hline & HadGEM2-AO & $\mathrm{H}$ & $\mathrm{H}$ & $\mathrm{H}$ & $\mathrm{H}$ & $\mathrm{L}$ & $\mathrm{L}$ & $M$ & $\mathrm{M}$ & $\mathrm{L}$ & $\mathrm{H}$ \\
\hline
\end{tabular}

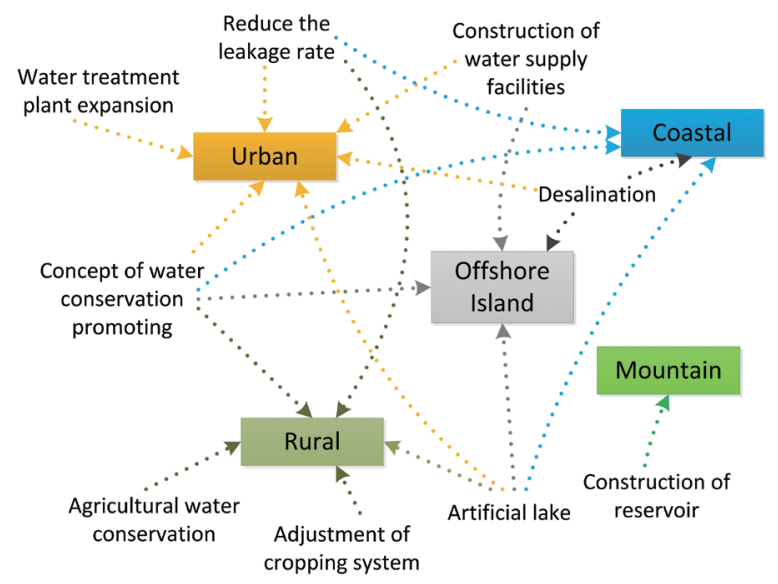

Fig. 14. Applicability of cross-space adaptation measures. (Color online only) 
Table 11. Planning spatial scales and contents of adaptation measures investigated in this study.

\begin{tabular}{c|c|c|l}
\hline No. & Adaptation measures & planning spatial scale & \multicolumn{1}{c}{ Content } \\
\hline (a) & Desalination & Urban, Coastal, Offshore island & Tainan desalination plant supply 100000CMD for public water \\
\hline (b) & Water treatment plant expansion & Urban & $\begin{array}{l}\text { Improving the capacity of Tanding water treatment plant from 180000CMD } \\
\text { to 195000CMD }\end{array}$ \\
\hline (c) & $\begin{array}{c}\text { Construction of water supply } \\
\text { facilities }\end{array}$ & Urban, Rural, Offshore island & Zenwen backup water treatment plant supply 65000CMD for public water \\
\hline (d) & Construction of reservoirs & Mountain & Nanhua 2 2 $^{\text {nd }}$ reservoir \\
\hline (e) & Artificial lake & $\begin{array}{c}\text { Urban, Rural, Offshore island, } \\
\text { Coastal }\end{array}$ & $\begin{array}{l}\text { Tainan lake-water storage in wet season, and supply 89500CMD raw water } \\
\text { in dry season. }\end{array}$ \\
\hline (f) & Promoting water conservation & $\begin{array}{c}\text { Urban, Rural, Offshore island, } \\
\text { Coastal }\end{array}$ & $\begin{array}{l}\text { Policy of water conservation (LPCD-250 \& Low growth of industrial water } \\
\text { demand) }\end{array}$ \\
\hline (g) & Agriculture water conservation & Rural & 20\% discount at agriculture water supply \\
\hline (h) & Adjustment of cropping systems & Rural & Left 50\% area fallow in first crop season \\
\hline (i) & Reduce leakage rate & Urban, Rural, Coastal & Reducing the leakage of Chianan canal from 25\% to 20\% \\
\hline
\end{tabular}

Table 12. Results of assessment indicators with future water demand scenario (II) and adaptation measures: VUL1 is vulnerability indicator1, VUL2 is vulnerability indicator 2, RES1 is resilience indicator 1, RES2 is resilience indicator 2, and AVA is availability indicator.

\begin{tabular}{c|c|c|c|c|c|c|c|c|c|c}
\hline \multirow{2}{*}{ Climate scenarios/adaptation measure } & \multicolumn{4}{|c}{ Public Water } & \multicolumn{5}{c}{ Agriculture Water } \\
\cline { 2 - 12 } & VUL1 & VUL2 & RES1 & RES2 & AVA & VUL1 & VUL2 & RES1 & RES2 & AVA \\
\hline Baseline & L & L & L & L & H & L & L & L & L & H \\
\hline HadGEM2-AO RCP8.5-L & H & H & H & H & L & L & M & M & L & H \\
\hline Desalination & H & H & H & H & L & L & M & M & L & H \\
\hline Water treatment plant expansion & H & H & H & H & L & L & M & M & L & H \\
\hline Construction of water supply facilities & H & H & H & H & L & L & M & M & L & H \\
\hline Construction of reservoirs & H & H & H & H & L & L & M & M & L & H \\
\hline Artificial lake & H & H & H & H & L & L & M & M & L & H \\
\hline Promoting water conservation & H & H & H & H & L & L & M & M & L & H \\
\hline Agriculture water conservation & H & H & H & H & L & L & M & H & H & M \\
\hline Adjustment of cropping systems & H & H & H & H & L & L & L & L & L & H \\
\hline Reduce leakage rate & H & H & H & H & L & L & L & M & L & H \\
\hline (a) + (f) + (h) & H & M & H & H & L & L & L & L & L & H \\
\hline (a) + (c) + (f) + (i) & H & M & H & H & L & L & L & M & L & H \\
\hline (a) + (d) + (f) & & L & L & L & H & L & M & M & L & H \\
\hline
\end{tabular}

the dry season, with no water shortage during the wet season, but long failure duration will still remain. The outcomes after implementing the combination of (a), (c), (f), and (i) are similar to the abovementioned. As for implementing the combination of (a), (d), and (f), which not only increase the water supply capability, but also decrease the water demand, the assessment indicators for public water will be low vulnerability, low resilience and high availability.

The effects of adaptation measures against climate change are listed below:

(1) The great increment of water demand cannot be met without implementing the combination of adaptation measures.

(2) Agriculture water conservation and adjustment of cropping systems can greatly reduce amounts of water de- mand in Tainan. They provide flexible cross-spatial advantages and can be implemented in urgent water shortage events. When the potential effect on crop yield is considered, reducing the leakage rate will be a better adaptation measure among all stakeholders.

(3) With the rapid growth of public water demand, the combination of various adaptation measures, including desalination, construction of reservoirs, and promoting water conservation, have the most significant effects in reducing the impacts of climate change.

\section{CONCLUSIONS}

This study developed a procedure for assessing the vulnerability and resilience of water resources using an 
integrated tool, TaiWAP. With the grading assessment indicators, the outcomes of adopting adaptation measures can be easily evaluated. Under the current situation, the water supply can meet the demand in Tainan, but agriculture water accounts for a huge part of total water usage, limiting the allocation of water resources. There are different climate change scenario results but the trend is toward decreasing discharge during the dry season. In addition, as long as the rapid growth of water demand is considered, the current water supply system cannot meet the water demand and will be a serious risk in the future. For the coming impact of climate change, adaptation measures and strategies are needed. Since the traditional ways to supply water cannot meet demand, it is important to develop new water sources and multi-purpose management when considering all stakeholders. In the meantime, the water resources conservation concept should also be promoted. Following the procedures practiced in this study, the decision makers can evaluate the applicability of adaptation measures, and the water resources strategies can be optimized for sustainable development. Future study should consider the cost and the time required to implement adaption measures. The advantages and feasibilities of cross space adaption measures should be further investigated.

Acknowledgements This study was supported by the Ministry of Science and Technology, Taiwan (MOST 1042621-M-002-002) through the National central University. English proofreading of this paper was gratefully helped by Debbie Nester. Valuable suggestions and constructive comments given by the Two Anonymous Reviewers are greatly appreciated.

\section{REFERENCES}

Allouche, J., 2011: The sustainability and resilience of global water and food systems: Political analysis of the interplay between security, resource scarcity, political systems and global trade. Food Pol., 36, S3-S8, doi: 10.1016/j.foodpol.2010.11.013. [Link]

Brenkert, A. L. and E. L. Malone, 2005: Modeling vulnerability and resilience to climate change: A case study of India and Indian states. Clim. Change, 72, 57-102, doi: 10.1007/s10584-005-5930-3. [Link]

Downing, T. E., R. E. Butterfield, B. Edmonds, J. W. Knox, S. Moss, B. S. Piper, and E. K. Weatherhead, 2003: Climate Change and the Demand for Water, Research Report, No. CPM-03-107, Stockholm Environment Institute Oxford Office, Oxford.

Haith, D. A., R. Mandel, and R. S. Wu, 1992: General Watershed Loading Function, Version 2.0, User's Manual, Cornell University, Ithaca, NY, USA.

Hamon, W. R., 1961: Estimating potential evapotranspiration. J. Hydraul. Div., 87, 107-120.

IPCC, 2013: Summary for Policymakers. In: Stocker, T.
F., D. Qin, G. K. Plattner, M. M. B. Tignor, S. K. Allen, J. Boschung, A. Nauels, Y. Xia, V. Bex, and P. M. Midgley (Eds.), Climate Change 2013: The Physical Science Basis, Contribution of Working Group I to the Fifth Assessment Report of the Intergovernmental Panel on Climate Change, Cambridge University Press, Cambridge, United Kingdom and New York, NY, USA, 3-29.

IPCC, 2014: Climate Change 2014: Impacts, Adaptation, and Vulnerability. Part A: Global and Sectoral Aspects, Contribution of Working Group II to the Fifth Assessment Report of the Intergovernmental Panel on Climate Change, Cambridge University Press, Cambridge, United Kingdom and New York, NY, USA, 1132 pp.

Jones, J. W., G. Hoogenboom, C. H. Porter, K. J. Boote, W. D. Batchelor, L. A. Hunt, P. W. Wilkens, U. Singh, A. J. Gijsman, and J. T. Ritchie, 2003: The DSSAT Cropping System Model. Eur. J. Agron., 18, 235-265, doi: 10.1016/S1161-0301(02)00107-7. [Link]

Li, M. H., W. Tien, and C. P. Tung, 2009: Assessing the impact of climate change on the land hydrology in Taiwan. Paddy Water Environ., 7, 283-292, doi: 10.1007/ s10333-009-0175-9. [Link]

Liu, T. M., C. P. Tung, K. Y. Ke, L. H. Chuang, and C. Y. Lin, 2009: Application and development of a decisionsupport system for assessing water shortage and allocation with climate change. Paddy Water Environ., 7, 301-311, doi: 10.1007/s10333-009-0177-7. [Link]

Piao, S., P. Ciais, Y. Huang, Z. Shen, S. Peng, J. Li, L. Zhou, H. Liu, Y. Ma, Y. Ding, P. Friedlingstein, C. Liu, K. Tan, Y. Yu, T. Zhang, and J. Fang, 2010: The impacts of climate change on water resources and agriculture in China. Nature, 467, 43-51, doi: 10.1038/nature09364. [Link]

Sullivan, C. A., 2011: Quantifying water vulnerability: A multi-dimensional approach. Stoch. Environ. Res. Risk Assess., 25, 627-640, doi: 10.1007/s00477-010-04268. [Link]

Tung, C. P. and D. A. Haith, 1995: Global-Warming Effects on New York Streamflows. J. Water Resour. Plan. Manage., 121, 216-225, doi: 10.1061/(ASCE)07339496(1995)121:2(216). [Link]

Tung, C. P., T. M. Liu, S. W. Chen, K. Y. Ke, and M. H. Li, 2014: Carrying capacity and sustainability appraisals on regional water supply systems under climate change. Br. J. Environ. Clim. Change, 4, 27-44, doi: 10.9734/BJECC/2014/8572. [Link]

Urich, C. and W. Rauch, 2014: Exploring critical pathways for urban water management to identify robust strategies under deep uncertainties. Water Res., 66, 374-389, doi: 10.1016/j.watres.2014.08.020. [Link]

Ventana, 2007: Vensim-DSS Reference Supplement, Ventana systems Inc. Available at https://vensim.com/docs/.

WRA, 2009: The Water Potential Demand Assessment 
and Management Strategy Review in Taiwan, Water Resources Agency, Ministry of Economic Affairs. (in Chinese)

Yoo, S. H., J. Y. Choi, W. H. Nam, and E. Hong, 2012:
Analysis of design water requirement of paddy rice using frequency analysis affected by climate change in South Korea. Agr. Water Manag., 112, 33-42, doi: 10.1016/j.agwat.2012.06.002. [Link] 